University of Nebraska - Lincoln

DigitalCommons@University of Nebraska - Lincoln

Faculty Publications, Department of Child, Youth, and Family Studies

Child, Youth, and Family Studies, Department of

2019

\title{
Contextual Factors Influence Professional Development Attendance Among Child Care Providers in Nebraska
}

Dipti Dev

University of Nebraska-Lincoln, ddev2@unl.edu

Aileen S. Garcia

South Dakota State University, aileen.garcia@sdstate.edu

Alison Tovar

University of Rhode Island, alison_tovar@uri.edu

Holly Hatton-Bowers

University of Nebraska-Lincoln, hattonb@unl.edu

Lisa Franzen-Castle

University of Nebraska-Lincoln, Ifranzen2@unl.edu

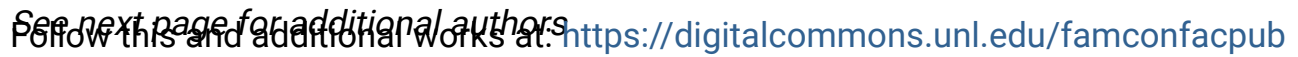

Part of the Developmental Psychology Commons, Family, Life Course, and Society Commons, Other Psychology Commons, and the Other Sociology Commons

Dev, Dipti; Garcia, Aileen S.; Tovar, Alison; Hatton-Bowers, Holly; Franzen-Castle, Lisa; Rida, Zainab; Reddish, Linda; Smith, Jasmin; Burger, Christy; Dinkel, Danae; Behrends, Donnia; Hulse, Emily; and Sheridan, Susan M., "Contextual Factors Influence Professional Development Attendance Among Child Care Providers in Nebraska" (2019). Faculty Publications, Department of Child, Youth, and Family Studies. 270.

https://digitalcommons.unl.edu/famconfacpub/270

This Article is brought to you for free and open access by the Child, Youth, and Family Studies, Department of at DigitalCommons@University of Nebraska - Lincoln. It has been accepted for inclusion in Faculty Publications, Department of Child, Youth, and Family Studies by an authorized administrator of DigitalCommons@University of Nebraska - Lincoln. 


\section{Authors}

Dipti Dev, Aileen S. Garcia, Alison Tovar, Holly Hatton-Bowers, Lisa Franzen-Castle, Zainab Rida, Linda Reddish, Jasmin Smith, Christy Burger, Danae Dinkel, Donnia Behrends, Emily Hulse, and Susan M.

Sheridan 


\title{
Contextual Factors Influence Professional Development Attendance Among Child Care Providers in Nebraska
}

\author{
Dipti A. Dev, $\mathrm{PhD}^{1}$; Aileen S. Garcia, $\mathrm{PhD}^{2}$; \\ Alison Tovar, $\mathrm{PhD}^{3}$; Holly Hatton-Bowers, $\mathrm{PhD}^{1}$; \\ Lisa Franzen-Castle, PhD, RD ${ }^{4}$; Zainab Rida, PhD, RD5; \\ Linda Reddish, MEd, RD ${ }^{6}$; Jasmin A. Smith, $\mathrm{MS}^{1}$; \\ Christy Burger, MS4; Danae Dinkel, $\mathrm{PhD}^{7}$; \\ Donnia Behrends, MS, RD ${ }^{6}$; Emily Hulse, $\mathrm{MS}^{8}$; \\ Susan Sheridan, $\mathrm{PhD}^{9}$
}

\footnotetext{
1 Department of Child, Youth and Family Studies, University of Nebraska-Lincoln, Lincoln, NE

2 Department of Counseling and Human Development, South Dakota State University, Brookings, SD

3 Department of Nutrition and Food Sciences, University of Rhode Island, Kingston, RI

4 Department of Nutrition and Health Sciences, University of Nebraska-Lincoln,

Lincoln, NE

5 Nebraska Department of Education, Lincoln, NE

6 University of Nebraska-Lincoln Extension, Lincoln, NE

7 Department of Health Promotion, Social, Behavioral Health Sciences, University of

Nebraska Omaha, Omaha, NE

8 Children's Hospital and Medical Center-Omaha, Omaha, NE

9 Nebraska Center for Research on Children, Youth, Families and Schools, Lincoln, $\mathrm{NE}$

Corresponding author - Dipti A. Dev, PhD, Department of Child, Youth and Family Studies, University of Nebraska-Lincoln, 255 Louise Pound Hall, 512 N 12th St, Lincoln, Nebraska 68588-0236; email: ddev2@unl.edu
}

Published in Journal of Nutrition Education and Behavior, 2019

doi 10.1016/j.jneb.2019.09.011

PMID 31708425

Copyright (c) 2019 Society for Nutrition Education and Behavior. Published by Elsevier Inc. Used by permission.

Accepted September 15, 2019; published 9 November 2019. 


\begin{abstract}
Objective: To examine contextual factors that may influence child care providers' motivators for attending nutrition-related training and their preferences and barriers to attending professional development training.

Design: Cross-sectional survey completed between January and April 2017.

Setting: Licensed child care programs $(n=1,490)$ across urban and rural Nebraska.

Participants: Child care center directors $(\mathrm{n}=336)$ and family child care home providers $(\mathrm{n}=1,154)$.

Main Outcome Measures: Motivators, preferences, and barriers of child care providers for attending professional development.

Analysis: Descriptive statistics and multiple logistic regression analyses were conducted.

Results: Top motivators for attending nutrition-related training included meeting licensure requirements and improving job performance. Child care providers most commonly selected preferences for receiving training included in-person and online delivery. Top barriers to obtaining training were schedule conflicts, accessibility, and cost. Child care centers and participants in the Child and Adult Care Food Program (CACFP) and Nutrition and Physical Activity Self-Assessment in Child Care (Go NAP SACC) were more likely to be motivated by licensure requirements. Rural providers were also more likely to report barriers such as inability to travel and limited access to training. Results revealed that child care type, geographic location, CACFP and Go NAP SACC participation can influence child care providers' motivators, preferences, and barriers to attending training. Conclusions and Implications: Results highlight the importance of offering professional development training that best fits child care providers' needs and preferences.
\end{abstract}

Keywords: child care providers, Child and Adult Care Food Program, professional development, rural, center vs. home-based child care

\title{
Introduction
}

About 20 million children in the US attend some child care where they consume up to 6 meals and snacks per day. ${ }^{1}$ Therefore, child care providers can play an essential role in fostering young children's growth and development. Currently, Nebraska ranks fifth in childhood obesity among children aged 2-4 years in the US²; thus, improving child care providers' knowledge and nutrition-related practices to combat childhood obesity is imperative. Professional development of child care providers is critical for the implementation of nutrition-related best practices and policies for shaping children's eating habits and preventing childhood obesity. ${ }^{3-5}$ Despite the need and benefits, engaging child care providers in professional development continues to be a challenge. ${ }^{6}$ Provider-level factors, such as personal beliefs, education, 
logistical challenges, and insufficient support, deter providers' ability to attend professional development. ${ }^{7}$

Although there is evidence that provider-level factors influence participation in professional development, ${ }^{7}$ limited information is available about the role of broader contextual factors. For example, contextual factors such as the type of child care (child care center [CCC] vs family child care home $[\mathrm{FCCH}]$ ) and geographic location (urban vs rural) may influence providers' ability to participate in professional development. Regarding the type of child care, as the first contextual factor, although both CCCs and FCCHs are licensed child care programs, they vary in many aspects. For example, CCCs are larger in size nonresidential facilities with more staff and children than FCCHs, which offer care to children in a provider's home. ${ }^{8,9}$ Geographic location is included as the second contextual factor because providers in rural areas have reported limited access to healthy foods. ${ }^{10,11}$ There are also noteworthy disparities in childhood obesity rates, with children in rural areas having 26\% higher odds of being classified as obese compared with urban children. ${ }^{12}$

Another contextual factor that may influence providers' professional development includes provider participation in federal food assistance programs and targeted nutrition interventions. The US Department of Agriculture Child and Adult Care Food Program (CACFP) serves approximately 4.2 million US children by providing financial reimbursement to child care providers, and, in response, child care providers are required to comply with meal pattern requirements, and serve nutritious meals to children. ${ }^{13}$ Recently, CACFP updated the meal pattern requirements to increase fruit and vegetable availability, increase whole grains, remove grain-based desserts, and reduce added sugars in breakfast cereals and yogurts. ${ }^{13}$ Changes in the CACFP menu requirements and providers' limited knowledge regarding these changes, ${ }^{14}$ warrants the need for professional development and may influence providers' motivation for attending training.

Finally, interventions such as the Nutrition and Physical Activity Self- Assessment for Child Care (Go NAP SACC) may influence child care providers' participation in professional development. Go NAP SACC is an updated version of NAP SACC, an evidence- based environmental intervention for improving nutrition and weight outcomes in children and has been widely implemented in child care programs across the US ${ }^{15}$ Go NAP SACC builds on the self-assessment, action 
planning, and educational tools used previously by adding updated assessment tools and expanding best practices related to childhood obesity prevention. ${ }^{16}$ Child care providers in Nebraska who participated in Go NAP SACC have demonstrated significant improvements in their nutrition practices, such as serving healthier foods and practicing responsive feeding with children. ${ }^{17}$ Over 4-6 months, providers participating in Go NAP SACC complete self-assessments; receive training, technical assistance, and incentives such as resources and in-service hours; and establish best practices for healthy environments in child care.${ }^{17}$ These factors associated with Go NAP SACC participation could influence providers' motivation and preferences for attending professional development.

The purpose of this study was to examine how contextual factors such as child care type (FCCH vs. CCC), location (urban vs. rural), and program participation (either CACFP or Go NAP SACC) impact professional development. Specifically, what contextual factors are related to child care providers' motivation for attending nutrition-related training and their preferences and barriers to attending general professional development training.

\section{Methods}

\section{Sampling Procedure and Participants}

Licensed child care programs from a list provided by the Nebraska Department of Health and Human Services ( $n=3,014$; across the state of Nebraska) were contacted to participate in this study. In January 2017, survey packets (including a cover letter, survey booklet, \$1 cash incentive, and postage-paid reply envelope) were sent through surface mail to all programs. A reminder postcard was sent to all nonresponders after 1 week. After 3 weeks, nonresponders were sent a second survey packet, excluding the $\$ 1$ incentive. Finally, all remaining nonresponders were contacted by phone between March and April of 2017 to provide a final reminder to complete the survey. The University of Nebraska-Lincoln Institutional Review Board approved this study, and all participants received the informed consent letter.

The survey was developed to cover relevant nutrition-related topics in child care. To avoid respondent fatigue and to ensure the reliability 
of responses, the cover letter included the purpose of the study, which was to develop professional development training that would directly benefit child care providers and the children in their care. The cover letter also emphasized that the survey offered an opportunity for providers to express their needs and challenges related to training opportunities.

The final sample included 1,592 respondents across urban and rural Nebraska, resulting in a 54.6\% response rate. For the current study, only CCCs and FCCHs were included. Head Start programs ( $\mathrm{n}=56$ ), which are federally funded and are required to meet Head Start Nutrition Performance Standards, as well as other programs ( $n=46$; e.g., community center, public school), were excluded. Thus, 1,490 child care programs were included in the analyses. The respondents identified primarily as either a CCC director $(n=336)$, answering on behalf of other providers in the center, or FCCH provider $(n=1,154)$. Both are referred to as the provider in this study.

\section{Measure}

The Healthy Children, Healthy State Nebraska Child Care Needs Assessment survey used in this study consisted of an 86-item paper questionnaire with items drawn from previously published research regarding implementation of, difficulty in, and barriers to best practices for foods served, feeding children, nutrition education and training, and parent engagement. ${ }^{8}$ Survey items were reviewed by an advisory committee comprising individuals with expertise in early childhood education, nutrition, policy, and survey methodology. Further, cognitive testing was conducted with 2 FCCHs and 1 CCC provider to check for face validity. ${ }^{18}$ Following the feedback from cognitive testing, the survey was edited to improve the readability of a few items.

For this study, survey items related to motivation, preferences, and barriers to attending training and contextual factors were included in the model. For each item assessing motivators, preferences, and barriers to participating in training, participants were asked to respond to the following 3 question prompts: (1) When you participate in nutrition-related training, what is your motivation for participating? (2) Which of the following are barriers that prevent you from obtaining training? (3) What is your preference when it comes to receiving training? Regarding contextual factors, participants were asked to 
indicate if they participated in CACFP and the Go NAP SACC program by choosing a yes or no response. The survey is available as Supplementary Data.

\section{Analysis}

The Statistical Package for Social Sciences (SPSS version 24.0, IBM Corp, Armonk, NY, 2016) was used to examine descriptive statistics for the entire sample to make comparisons across groups. Furthermore, 3 separate multiple logistic regression analyses were conducted to estimate the association of each binary independent variable, while controlling for the effects of the other 3 independent variables (child care type $[\mathrm{O}=\mathrm{FCCH} ; 1=\mathrm{CCC}]$, location [O = urban; 1 = rural], CACFP participation [o = no; $1=$ yes], and Go NAP SACC participation [o = no; 1 = yes]) with their likelihood of reporting yes ( $0=$ no; $1=$ yes) to various motivations (10 items), preferences ( 6 items), and barriers to attending training ( 9 items) as binary dependent outcomes. As multiple comparisons were conducted, a Bonferroni adjusted alpha level of 0.0005 (0.05/100 comparisons) was used to determine statistical significance.

\section{Results}

Most of the respondents were white (94.2\%), and 73\% indicated having some college or higher educational background. Table 1 provides the sample demographic characteristics. The results of this study are presented in 3 sections. Each section presents the results of logistic regression analyses for (1) motivations for attending nutrition- related training, (2) preferences for attending training, and (3) barriers to attending training. For all the logistic regression results, the top responses with the highest percentages of provider responses are first presented, followed by the level of significance. Standardized coefficients are presented in Tables 1-3, together with standard errors and odds ratios (OR). 
Table 1. Demographic Characteristics by Child Care Type (CCC and FCCH) and Location (Rural and Urban)

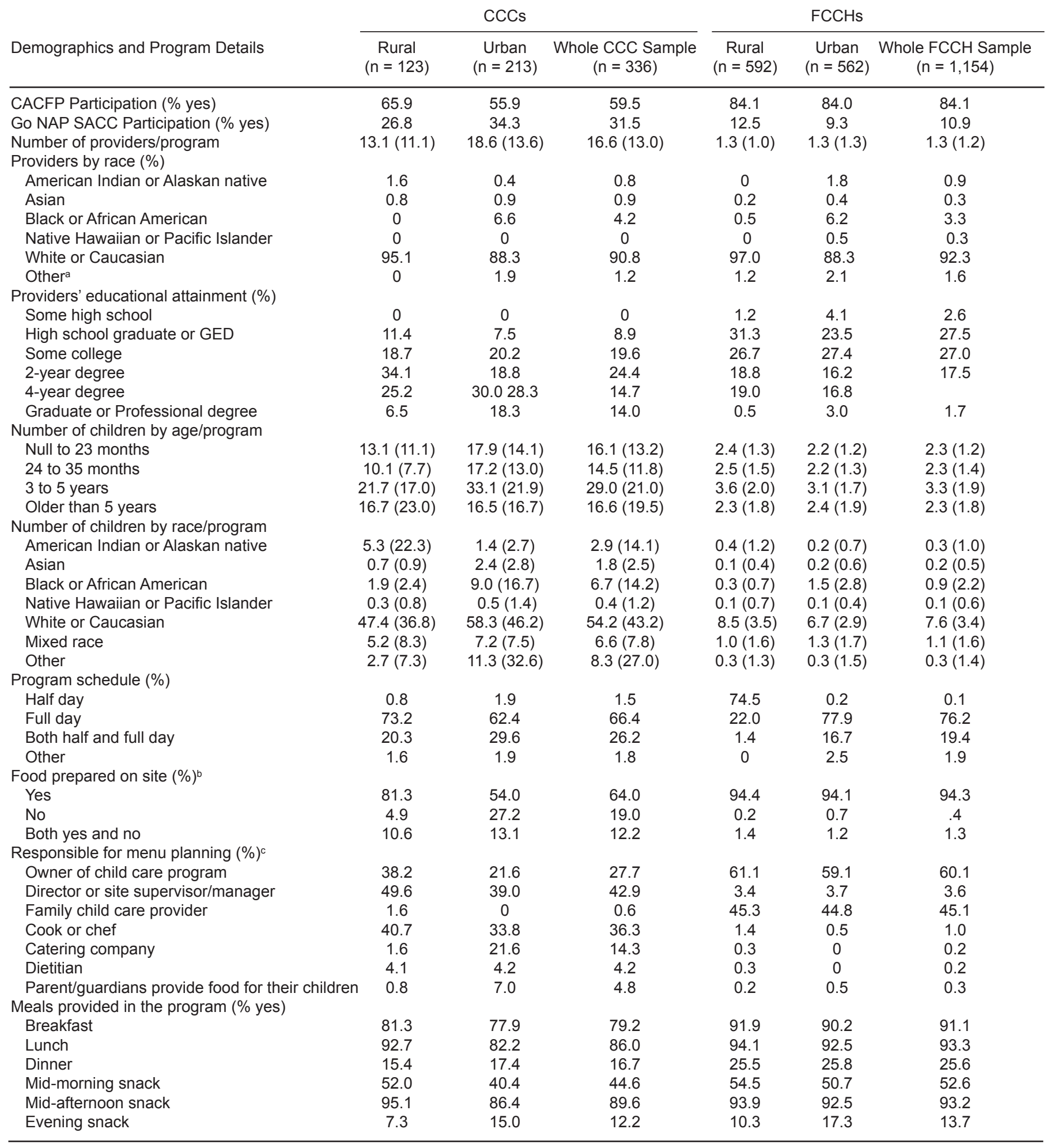

CACFP indicates Child and Adult Care Food Program; CCC, child care center; FCCH, family child care homes; GED, general education development; Go NAP SACC, Go Nutrition and Physical Activity Self-Assessment for Child Care; CCCs, child care center; FCCHs, family child care home.

a. The "Other" option was for those who did not identify with the given racial categories. Sample responses to "Other" included French, East Indian, and Middle Eastern, among others;

b. The numbers do not add up to $100 \%$ as some respondents chose to skip this question.

c. The numbers could exceed $100 \%$ as this was a multiple-response question as more than one type of staff person could be responsible for menu planning.

Notes: Data are presented as \% or mean (SD) unless otherwise specified. Total sample size (n) was 1,490. 


\section{Motivation for Attending Nutrition-Related Training}

Motivators for attending professional development training most commonly identified by child care providers included licensure requirements (80.7\%), staying updated with best practices (67.9\%), and improving job performance (59.9\%; Table 2). In comparing CCCs and FCCHs, CCCs had a higher likelihood of reporting a CACFP requirement as motivation to attend training ( $\mathrm{OR}=2.59$; 95\% confidence interval $[\mathrm{CI}], 1.52-4.42)$. Additionally, providers participating in CACFP were significantly more likely to be motivated by licensure or regulatory requirements ( $\mathrm{OR}=2.34$; $\mathrm{CI}, 1.49-3.70)$ and CACFP requirements (OR $=85.984$; CI, 38.57-191.71). Go NAP SACC participants were more likely to report being motivated by 2 factors- to grow and improve job performance and better meet children's needs compared with their nonparticipating counterparts.

\section{Preferences for Training}

Preferences for training most commonly selected by child care providers included: in-person training (61.2\%), attending 1-day conferences with multiple sessions (49.7\%), and online learning modules with videos that can be viewed at any time (49.1\%; Table 3). Child care centers were more likely to prefer live webinars (OR = 2.99; CI, 2.07-4.34) as compared with FCCHs. Those who participated in Go NAP SACC were more likely to prefer attending conferences (OR = 1.863; CI, 1.32-2.62), and ongoing mentorship and coaching (OR = 2.689; CI, 1.61-4.49) compared with the non-Go NAP SACC participants.

\section{Barriers to Attending Training}

Table 4 presents different barriers to attending training encountered by child care providers. The most commonly selected barriers included: scheduled training does not fit within the work schedule (49.1\%), unable to travel to the training location (28.4\%), and the cost of training (28.3\%). Providers in rural areas had a greater likelihood of reporting an inability to travel to the training location $(\mathrm{OR}=$ 3.24; CI, 2.31-4.54) and training being hard to find in their area (OR = 3.66; CI, 2.43-5.52) compared with urban providers. 


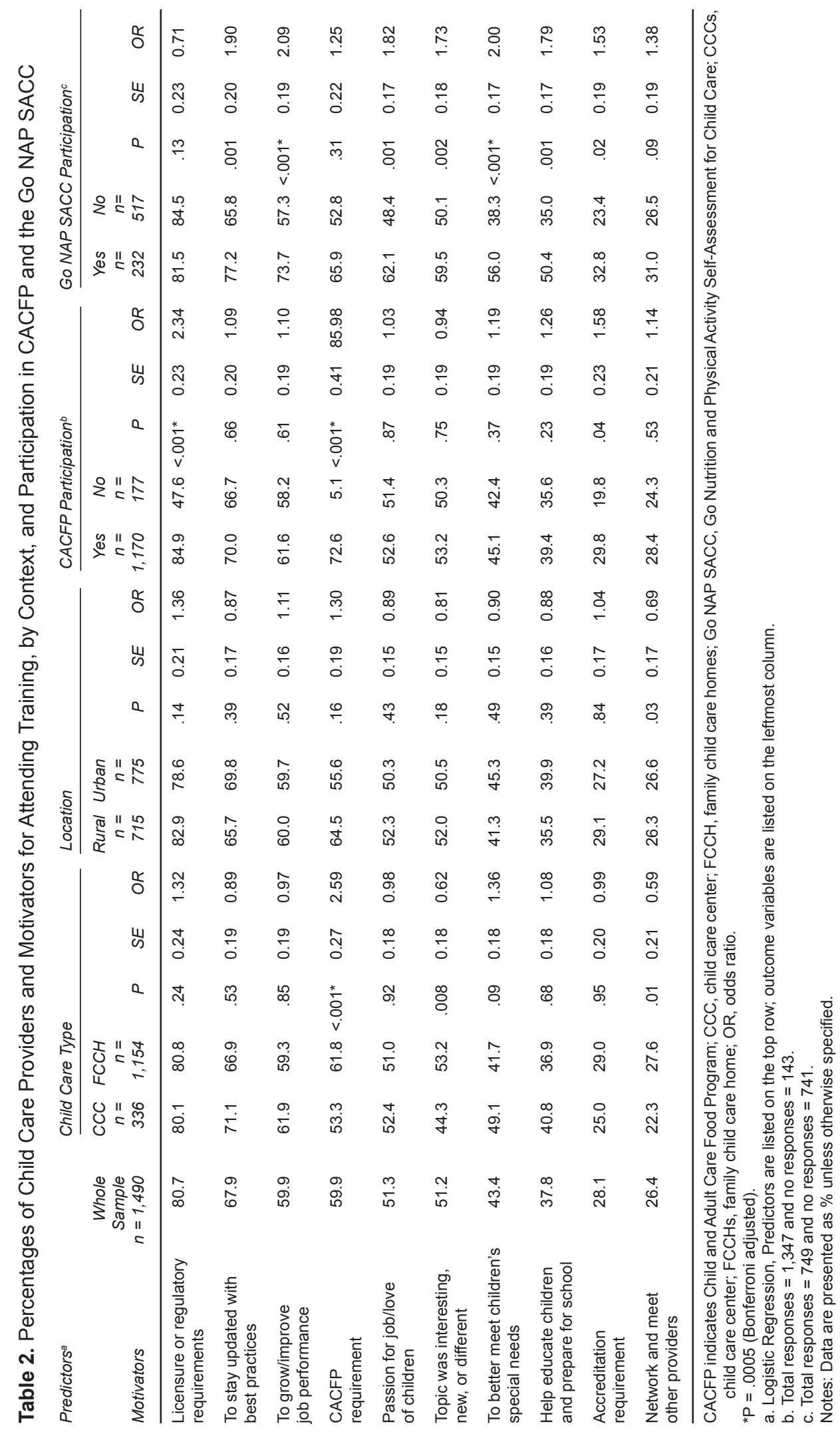




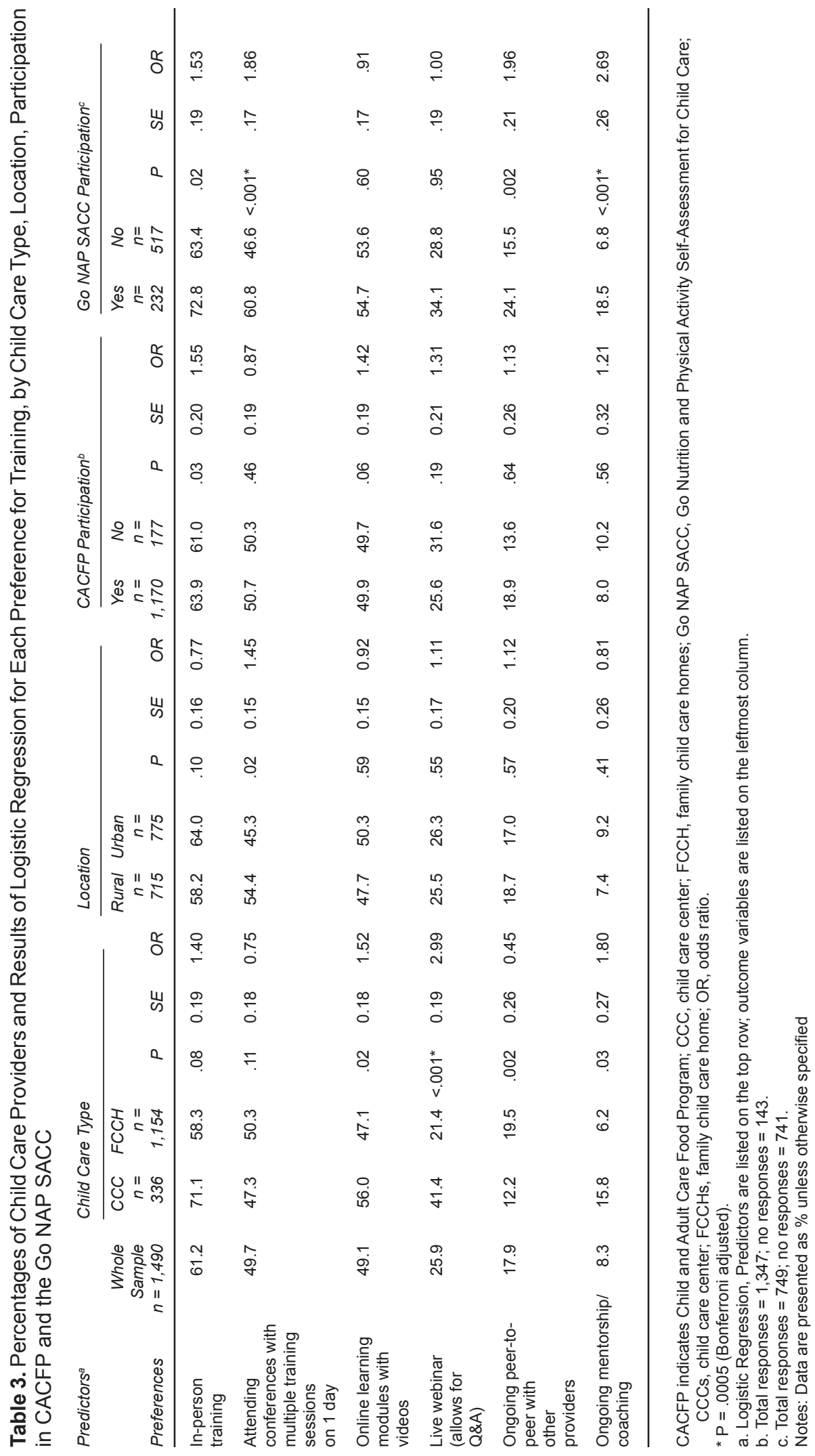




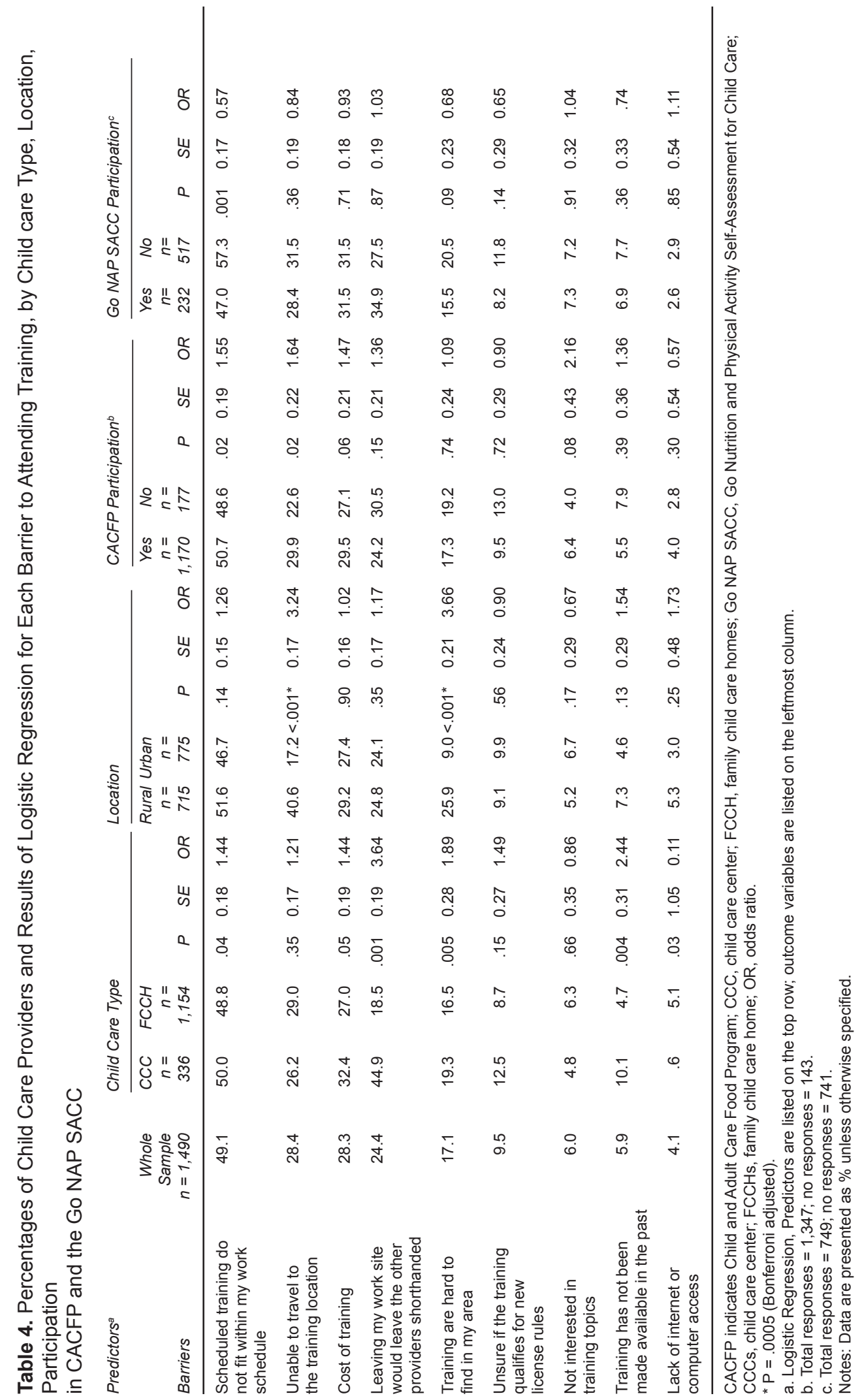




\section{Discussion}

Given the childhood obesity epidemic, it is critical to ensure that child care providers receive professional development on nutrition-related best practices to shape children's eating habits. Therefore, the objective of this study was to understand the role of contextual factors in providers' motivators for attending nutrition-related training as well as preferences and barriers to attending professional development in general. Given the important role that child care providers play in the development of children's health behaviors, understanding these factors can help improve providers' participation in professional development. Child care type, location, CACFP and Go NAP SACC participation influenced child care providers' motivators, preferences, and barriers to attending training. As such, understanding the role of these contextual factors can help tailor the delivery of professional development training aiming to improve nutrition-related behaviors of children. The results offer implications for researchers, nutrition educators, and policymakers.

The results of this study showed that licensure requirements were one of the most commonly selected motivators for attending training. The Centers for Disease Control and Prevention recommend that licensing and state's quality rating and improvement systems include training requirements regarding nutrition and physical activity-related topics. ${ }^{19}$ Following this recommendation, Nebraska providers who participate in Go NAP SACC receive points toward maintaining a higherquality rating, referred to as the Step Up to Quality Program. ${ }^{20}$ In addition, fulltime Nebraska child care providers are required to receive 12 hours of annual training and cooks or providers who serve food need at least 4 hours of food safety training every year. ${ }^{21}$ However, training with regards to nutrition or physical activity is not required to maintain licensure. The Centers for Disease Control and Prevention recommends including nutrition and physical activity training as part of licensure for child care providers; however, this is not a requirement in Nebraska. ${ }^{19}$ Meeting licensure requirements was the most commonly selected motivator by Nebraska child care providers for participating in nutrition-related training. Therefore, child care providers may be more motivated to attend nutrition-related training if Nebraska strengthened the licensure requirements by mandating training in nutrition as part of licensure. 
Whereas licensure requirements were a top motivator for attending training, program characteristics also played an important role in increasing the likelihood that a particular motivator would be selected. For example, CCCs, as compared with FCCHs, were more likely to attend training because it is a CACFP requirement. These results highlight the differences between these 2 settings (CCCs and FCCHs) and the need to tailor professional development training differently. Providers in FCCHs may be more likely to choose professional development opportunities based on their interests because fewer $\mathrm{FCCH}$ providers participate in CACFP and do not need to meet these requirements. In addition, because $\mathrm{FCCH}$ providers often serve in the role of a director as well as providers, FCCHs may have more choice in attending training. 8,9 With some studies reporting that less formal types of care, including FCCHs, are more highly associated with childhood obesity, ${ }^{22}$ it is essential to engage $\mathrm{FCCH}$ providers in professional development by assessing the health-related topics they are interested in learning more about. CACFP participation was also an important predictor of motivation for providers to attend nutrition-related training. This finding is important as other studies find that CACFP participation improves the quality of foods offered in child care. ${ }^{23,24}$ Because of the mandated requirements that result from CACFP participation, efforts to increase CACFP enrollment may help increase participation in nutrition-related professional development training.

Aside from licensure requirements, adjusting for other contextual factors, Go NAP SACC participants were more likely to choose additional motivators as compared with non-Go NAP SACC participants. These motivators included intrinsic motivators such as a desire to improve job performance and to better meet children's needs. Go NAP SACC is centered on meeting best practices related to children's nutrition, which may contribute to providers being more likely to choose motivators related to the desire to learn about nutrition education and to help children develop healthy eating habits. ${ }^{25,26}$ Furthermore, participation in Go NAP SACC is entirely voluntary; thus, those who have completed the process are likely highly motivated to improve their quality of care to promote children's healthy eating and obesity prevention.

Overall, the top 3 barriers that prevented providers from obtaining training were that the scheduled training did not fit their work schedule, providers were unable to travel to the training location, and the 
cost of training was too high. In addition, rural providers were more likely than urban providers to report the inability to travel as a barrier to obtaining training and that training was hard to find in their area. These findings are consistent with previous research reporting that rural providers are more often concerned regarding access to training compared with urban providers. ${ }^{27}$ Together, these findings highlight how geographic location of the child care setting may contribute to unique challenges in obtaining training for rural providers. Online professional development offerings may be particularly convenient and useful for rural providers who experience limited in-person local training options..$^{28,29}$ Regardless of child care type and location, providers did not report lack of internet or computer access as a prominent barrier (only $4.1 \%$ of the entire sample reported it as a barrier). Although the potential for online professional development is a promising avenue for training rural child care providers in Nebraska, a recent study reported that greater than $70 \%$ of Minnesota rural child care providers indicated they preferred an in-person training delivery mode despite scheduling and travel barriers. ${ }^{27}$ As about $50 \%$ of Nebraska providers preferred online training, future studies are needed to determine strategies to improve the feasibility and acceptance of online distance training with rural child care providers.

The results of this study should be interpreted in light of their strengths and limitations. The strengths of this study include the large state-wide representative sample and inclusion of varying contextual factors that may influence providers' motivators, preferences, and barriers for participating in professional development. However, despite the large sample size, this study only included child care providers in Nebraska, which could limit the generalizability of the results. The sample was also fairly racially homogeneous, a reflection of the racial distribution in Nebraska, and could also limit generalizability of the findings. Although we used a regression model to predict the association between the contextual variables and the motivators, preferences, and barriers to training, the use of single time-point data can only demonstrate a correlation. For example, we found that Go NAP SACC participants selected more motivators for attending nutrition-related training, suggesting that the Go NAP SACC program increases the number of motivating factors to attain these types of training. However, it is also plausible that those providers who decided to participate in Go NAP SACC were already motivated to attend 
nutrition-related training. In addition, this study collected data only from licensed child care programs registered with the Nebraska Department of Education, but not license-exempt child care programs that care for 3 or fewer children from more than 1 family. ${ }^{30}$ Finally, the center director or FCCH provider completed the survey and perspectives from other child care staff were not reported in this study. Future studies could incorporate data from multiple data sources (e.g., assistant director, curriculum coordinators, program directors, and lead teachers) or methods (e.g., interviews, focus groups) to overcome this limitation.

\section{Implications for Research and Practice}

The results from this study indicate that professional development training designed to improve child care practices consider not only the type of training needed, but also the unique contextual factors related to child care providers' motivations, preferences, and barriers with attending training. First, given that the top motivator to attend training was licensing requirements, ensuring that these requirements include nutrition and physical activity training is important. Second, in-person training and attending conferences remained the most preferred modes of training, but participants who expressed these preferences also reported challenges with access to training that varied by program type and rural-urban context. Thus, nutrition educators are encouraged to look at elements that contribute to the increased appeal of in-person training and consider incorporating these elements into online platforms where applicable. For example, making training websites interactive and having an online coach or trainer available for questions may help bridge the differences between in-person and online training. This sort of hybrid or blended format incorporates the desirable features of in-person and online training and could also cater to child care providers' needs. Given the higher childhood obesity rates in rural areas, ensuring that rural providers have access to training is critical. ${ }^{31}$

Past research has shown that hybrid online courses, when effectively designed, can positively impact the learner's engagement and learning. ${ }^{32}$ These blended approaches could also incorporate professional learning communities wherein child care providers can learn 
from their peers and have increased opportunities for networking. Professional learning communities occur when peers meet for some time and collectively share their motivations, barriers, or strategies typically with a skilled facilitator guiding the group's discussion and reflections. ${ }^{33-35}$ Providers may improve their teaching and skills by learning from the contributions, experience, and knowledge of peers. ${ }^{34,35}$ Successful professional learning communities support providers' growth by maintaining confidentiality, keeping the group provider-driven, and ensuring that the facilitator does not rush the professional development process. ${ }^{35,36}$ This approach could be tailored to address providers' needs at multiple levels because professional learning communities can be formed based on a variety of variables; role, location, topics of interest, or concerns.

It is also interesting that most child care providers, irrespective of the context, selected attending an in-person training followed by participating in conferences with multiple training sessions on a single day and online learning modules with videos as the most preferred training modes. Regarding the influence of contextual factors on training preferences, CCCs preferred viewing a live webinar compared with FCCHs. This difference is likely because of availability of additional staff in CCCs than FCCHs. Moreover, surveys were largely completed by directors in CCCs who may have greater availability to attend a live webinar during the day. These results indicate that future research examines how the time and duration with which training is offered may influence CCCs and FCCHs motivation to attend nutrition and childhood obesity prevention training.

Participation in Go NAP SACC is another important contextual factor to consider in the delivery of training. Child care providers participating in Go NAP SACC were more likely to choose ongoing mentorship and ongoing peer-to-peer interactions as a preferred form of training. In addition, Go NAP SACC participants preferred attending conferences with multiple training sessions in a single day and ongoing mentorship and coaching as compared with non- Go NAP SACC participants. In completing the survey, Go NAP SACC providers and directors with more experience receiving technical assistance and mentorship may have experienced benefits with this form of professional development. As such, non-Go NAP SACC participants may have less experience and interest in receiving training in this way. Future 
studies could delve into additional characteristics that motivate comfort and interest of child care providers to receive training.

Conflicting schedules, accessibility, and cost were reported as barriers for child care providers to obtain training. Therefore, centers and organizations that offer training are encouraged to consider providing substitute teachers and providers and bringing the training or networking opportunity to the providers' area of work. These options may minimize travel time and reduce training costs. As highlighted in this study, providers have multiple motivators and preferences to engage in professional development training to meet various requirements and improve their child care practices. Addressing these barriers to training may help increase providers' participation in professional development and hence the quality of their work. With 20 million children attending child care paired with a growing childhood obesity epidemic, ${ }^{1}$ ensuring adequate professional development and training of providers will ultimately benefit the children in their care.

Acknowledgments - This work was supported by the US Department of Agriculture National Institute of Food and Agriculture, Hatch Project 1011204, and the Nebraska Agricultural Experiment Station. The authors wish to thank all the providers who contributed to this research project and the advisory committee for providing feedback on the survey.

Supplementary data related to this article follows the References.

\section{References}

1. Laughlin L. Who's minding the kids? Child Care Arrangements: Spring 2011. Washington, DC: US Census Bureau; 2013.

2. Trust for America's Health and Robert Wood Johnson Foundation. The State of Obesity in Nebraska. Washington, DC: Robert Wood Johnson Foundation; 2016. https://stateofobesity.org/states/ne

3. Sigman-Grant M, Christiansen E, Fernandez G, et al. Child care provider training and a supportive feeding environment in child care settings in 4 States, 2003. Prev Chronic Dis. 2011;8: A113.

4. Van Stan S, Lessard L, Dupont Phillips K. The impact of a statewide training to increase child care providers' knowledge of nutrition and physical activity rules in Delaware. Child Obes. 2013;9:43-50. 
5. Kakietek J, Dunn L, O’Dell SA, Jernigan J, Kettel Khan L. Training and technical assistance for compliance with beverage and physical activity components of New York City's regulations for early child care centers. Prev Chronic Dis. 2014;11: E177.

6. Roberts AM, Iruka IU, Sarver SL. Nebraska early childhood workforce survey: a focus on providers and teachers. Omaha, NE: The Buffet Early Childhood Institute; 2017. https://buffettinstitute.nebraska.edu/-/media/beci/docs/ workforce-survey-reportfinal.pdf?la=en

7. Whitebook M, McLean C, Austin L. Early Childhood Workforce Index- 2016. Berkeley, CA: University of California, Berkeley; 2016. http://cscce.berkeley. edu/files/2016/Early-Childhood-Workforce-Index-2016.pdf

8. Nanney MS, LaRowe TL, Davey C, Frost N, Arcan C, O'Meara J. Obesity prevention in early child care settings: a bistate (Minnesota and Wisconsin) assessment of best practices, implementation difficulty, and barriers. Health Educ Behav. 2017;44:31-32.

9. Kim J, Shim JE, Wiley AR, Kim K, McBride BA. Is there a difference between center and home care providers' training, perceptions, and practices related to obesity prevention? Matern Child Health J. 2012;16:1559-1566.

10. Battista RA, Oakley H, Weddell MS, Mudd LM, Greene JB, West ST. Improving the physical activity and nutrition environment through self-assessment (NAP SACC) in rural area child care centers in North Carolina. Prev Med. 2014;67:S10-S16.

11. Liese AD, Weis KE, Pluto D, Smith E, Lawson A. Food store types, availability, and cost of foods in a rural environment. J Am Diet Assoc. 2007;107:1916-1923.

12. Johnson JA, Johnson AM. Urban-rural differences in childhood and adolescent obesity in the United States: a systematic review and meta-analysis. Child Obes. 2015;11:233-241.

13. United States Department of Agriculture. Child and Adult Care Food Program: Meal Pattern Revisions Related to the Healthy, Hungry-Free Kids Act of 2010; Final Rule. 7 CFR Parts 210, 215, 220. Fed Regist. 2016;81:24348- 24383. https://www.gpo.gov/fdsys/pkg/FR-2016-04-25/pdf/2016-09412.pdf

14. Rida Z, Burger C, Dev D, Smith J, Hasnin S. Assessment of nutrition knowledge of childcare providers regarding the implementation of the 2017 CACFP meal pattern update. Am J Health Educ. 2018;49:384-394.

15. Ward DS, Benjamin SE, Ammerman AS, Ball SC, Neelon BH, Bangdiwala SI. Nutrition and physical activity in child care: results from an environmental intervention. Am J Prev Med. 2008;35: 352-356.

16. The University of North Carolina at Chapel Hill. NAPP SACC. 2018. https:// gonapsacc.org/history Accessed May 3, 2019.

17. Dev DA, Williams N, Iruka I, et al. Improving the nutrition and screen time environment through self-assessment in family childcare homes in Nebraska. Public Health Nutr. 2018;21:2351-2359.

18. Willis GB. Cognitive Interviewing. A "how to" guide. Evaluation. 1999;5:1-37. 
19. Centers for Disease Control and Prevention. The spectrum of opportunities framework for state-level obesity prevention efforts targeting the early care and education setting. Atlanta, GA: Centers for Disease Control and Prevention; 2018. https://www.cdc.gov/obesity/strategies/early-care-education/pdf/ TheSpectrumofOpportunitiesFramework_May2018_508.pdf Accessed May 3, 2019.

20. Step Up to Quality. GO NAP SACC. https://www.education.ne.gov/ stepuptoquality/providers-educators/enrolled-progams/go-nap-sacc/ Accessed May 3, 2019.

21. Nebraska Department of Health and Human Services. Title 391 children's services licensing. 2013. http://dhhs.ne.gov/Pages/Title-391.aspx Accessed June 19, 2019.

22. Benjamin SE, Rifas-Shiman SL, Taveras EM, et al. Early child care and adiposity at ages 1 and 3 years. Pediatrics. 2009;124:555-562.

23. Dev DA, McBride BA, Harrison K. Academy of Nutrition and Dietetics Benchmarks for Nutrition in child Care 2011: are child-care providers across contexts meeting recommendations? J Acad Nutr Diet. 2013;113: 1346-1353.

24. Andreyeva T, Henderson KE. Center-reported adherence to nutrition standards of the child and adult care food program. Child Obes. 2018;14:421-428.

25. Dev DA, Speirs KE, McBride BA, Donovan SM, Chapman-Novakofski K. Head Start and child care providers' motivators, barriers and facilitators to practicing family-style meal service. Early Child Res Q. 2014;29: 649-659.

26. Dev DA, Carraway-Stage V, Schober DJ, McBride BA, Kok CM, Ramsay S. Implementing the academy of nutrition and dietetics benchmarks for nutrition education for children: child-care providers' perspectives. J Acad Nutr Diet. 2017;117:1963-1971.e2.

27. Larson N, Loth KA, Nanney MS. Staff training interests, barriers, and preferences in rural and urban child care programs in Minnesota. J Nutr Educ Behav. 2019;51:335-341.

28. Weigel DJ, Weiser DA, Bales DW, Moyses KJ. Identifying online preferences and needs of early childhood professionals. Early Child Res Pract. 2012;14:1-20.

29. McCann BM. The effectiveness of Extension in-service training by distance: perception versus reality. J Ext. 2007;45:1FEA4.

30. Nebraska Department of Health and Human Services. Child Care Licensing. http://dhhs.ne.gov/licensure/Pages/Child-Care-Licensing.aspx.pdf Accessed June 19, 2019.

31. Lutfiyya MN, Lipsky MS, Wisdom-Behounek J, Inpanbutr-Martinkus M. Is rural residency a risk factor for overweight and obesity for US children? Obesity. 2007;15:2348-2356.

32. Shea J, Joaquin ME, Gorzycki M. Hybrid course design: promoting student engagement and success. J Public Aff Educ. 2015;21:539-556.

33. Ardichvili A, Page V, Wentling T. Motivation and barriers to participation in virtual knowledge-sharing communities of practice. J Knowl Manag. 2003;7:64-77. 
34. Wenger E. Communities of practice and social learning systems. Organ. 2000;7:225-246.

35. Curtis D, Lebo D, Cividanes WCM, Carter M. Reflecting in Communities of Practice: a Workbook for Early Childhood Educators. St. Paul, MN: Redleaf Press; 2013:414.

36. Schachter RE, Gerde HK, Hatton-Bowers H. Guidelines for Selecting Professional Development for Early Childhood Teachers. Early Child Educ J. 2019;47:395-408.

Supplementary data (survey instrument) follows. 


\section{Healthy Children, Healthy State Nebraska Childcare Needs Assessment Survey}

We ask the survey be filled out by one director or provider most familiar with the childcare program's nutrition practices. However, you may come across questions that you think someone else in your program could answer more easily than you. If so, PLEASE FEEL FREE TO ASK YOUR STAFF FOR HELP.

- These questions ask about practices in your preschool classroom (2-5 year old) or Head Start program, NOT infant classroom or your Early Head Start program (if you have one). Please answer questions about your preschool classroom with children aged 2-5 years.

- Childcare providers are individuals who have direct contact with preschoolers (2-5 years), and are responsible for supervising meals or snacks for preschool children.

- Please answer about what is currently happening in your program, unless a question asks about another time period.

- We do not expect you or your staff to consult any administrative records in order to complete the survey.

- If you are unsure about how to answer a question, please give the best answer you can rather than leaving it blank.

\section{About Your Program}

1. Which of the following best describes your program?
a. Childcare center
Yes No
b. Family childcare home
$\mathrm{O} O$
c. Head Start
00
d. Other (please specify):

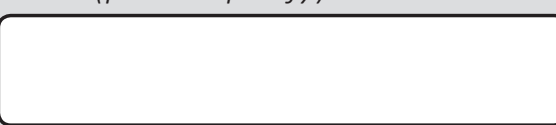

2. What is the total number of children in your childcare program?

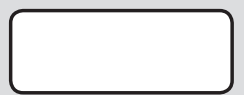

3. On a typical day, how many children in your program are in the following age categories?

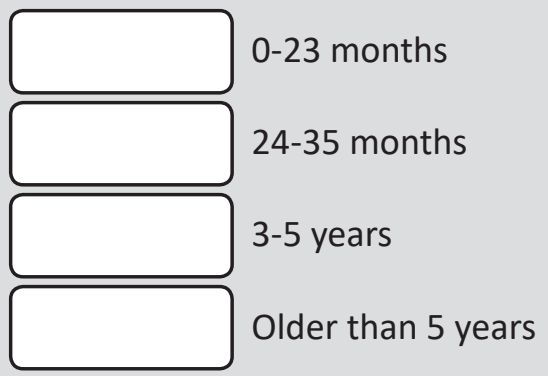

4. On a typical day, how many children in your program are Hispanic or Latino/a/x? (please give your best estimate)

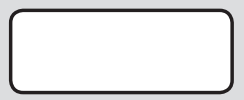

5. On a typical day, approximately how many children in your program are of the following racial backgrounds? (please give your best estimate)

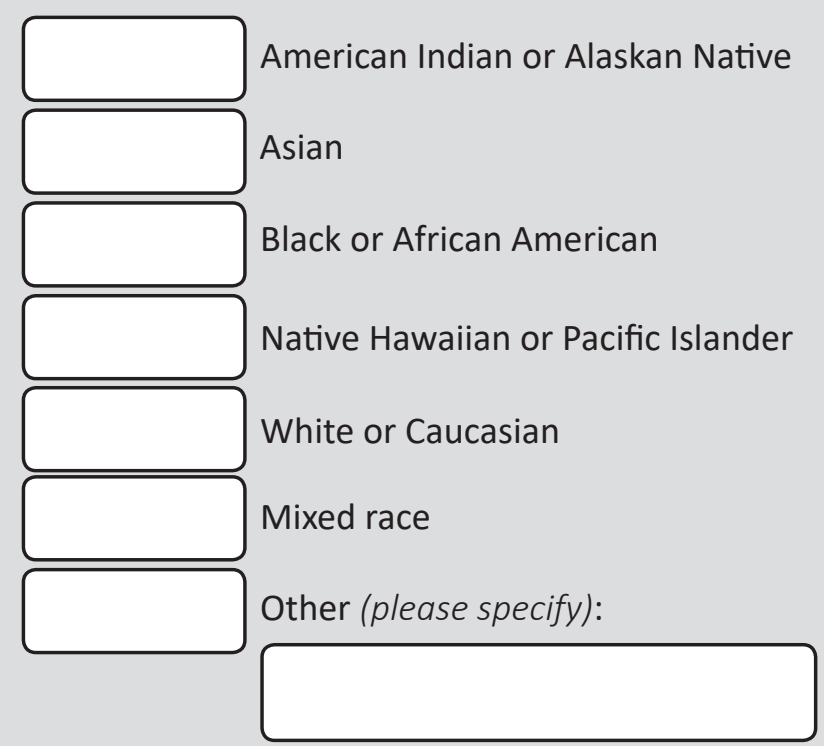

6. What is the total number of childcare providers employed at your program?

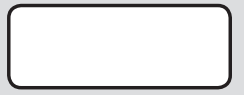

7. Which of the following best describes your program?

Half-day

OFull-day

Both half and full day

O Other (please specify): 


\section{Serving Foods and Beverages}

\section{Is food prepared on-site?}

Yyes
No
Both yes and no (please explain):

9. Who is responsible for menu planning? (check all that apply)

$\square$ Owner of childcare program

$\square$ Director or site supervisor/manager

$\square$ Family childcare provider

$\square$ Cook or chef

$\square$ Catering company

$\square$ Dietician

$\square$ Parents/guardians provide food for their children

$\square$ Other (please specify):
10. In which of the following does your childcare program participate?

a. Child and Adult Care Food Program by Yes No USDA, which provides reimbursement for foods served (CACFP)

b. Nutrition and Physical Activity Self-Assessment for Child Care (Go NAP SACC)

c. NE Step Up to Quality

d. National Association for the Education of Young Children (NAEYC)

11. Please indicate which of the following are provided in your childcare program?

No (Usually brought Yes from home)
a. Breakfast
$0 \quad 0$
b. Lunch
$0 \quad 0$
c. Dinner
0
d. Mid-morning snack
e. Mid-afternoon snack
0
f. Evening snack
0
0
O

\section{Serving Foods and Beverages: Difficulty Level}

$\begin{gathered}\text { Is your program } \\ \text { currently doing this? }\end{gathered}$
12. Serve fruit at least one time a day (Please do not
include fruit juice)
13. Serve vegetables at least one time per day (Please
do not include French-fries, tater tots, hash browns or
dried beans)
14. Prepare cooked vegetables without adding meat fat,
margarine, lard, or butter
15. Serve milk that is skim (nonfat) or 1\% to children ages
2 years and older
16. Serve only unflavored skim (nonfat) or $1 \%$ milk to
children ages 2 years and older
17. Serve meat or meat alternatives that are lean or low
fat every time meats or meat alternatives are served
(This includes skinless, baked or broiled chicken; baked
or broiled fish; ground beef or turkey that is at least
93\% lean and cooked in a low fat way; low-fat dairy
foods; baked, poached or boiled eggs and dried beans)

How difficult is it to do (or potentially do)?

Not at all A little Kind of Very difficult difficult difficult difficult 


\section{Is your program currently doing this?}

Yes No

18. Serve fried or pre-fried meats less than one time a week or never (This includes breaded and frozen chicken nuggets and fish sticks)

19. Serve high sugar/high fat foods less than one time per week or never (This includes cookies, cakes, doughnuts, muffins, ice cream and pudding)

20. Serve high fiber, whole grain foods at least once a day (This includes whole wheat bread, whole wheat crackers, oatmeal, brown rice, Cheerios, and whole grain pasta)

21. Never serve sugary drinks (This includes Kool-Aid, fruit or sport drinks, sweet tea)

22. Use either healthy foods or non-food treats (such as stickers) to celebrate holidays, birthdays, and other special events

O $O$

$0 \quad 0$

00

0
0
How difficult is it to do (or potentially do)?

Not at all A little Kind of Very difficult difficult difficult difficult

$\begin{array}{llll}0 & 0 & 0 & 0 \\ 0 & 0 & 0 & 0 \\ 0 & 0 & 0 & 0 \\ 0 & 0 & 0 & 0 \\ 0 & 0 & 0 & 0\end{array}$

\title{
Serving Foods and Beverages: Barriers
}

The list below includes possible barriers to providing healthier meals and snacks. For each statement, please answer yes if it is a barrier your program faces, or no if not.

Yes No

23. Not enough money to cover the cost of serving healthier meals and snacks

0

24. Lack of control over the types of meals and snacks that are delivered to us

25. Those preparing meals and snacks lack the knowledge to prepare healthier foods and beverages $\bigcirc \quad \bigcirc$

26. Those preparing meals and snacks lack the time to prepare healthier foods and beverages

27. Children would not like the taste of healthier meals and snacks

28. Parents/guardians do not support the idea of serving children healthier meals and snacks

29. Limited space for food storage, such as refrigerator and cabinet space

30. Lack of availability of healthy foods in my area

31. Lack of support from other providers

32. Other areas in our program have higher priority than nutrition at this time

33. So many different recommendations that providers do not know which to follow

34. Unsure which foods can be reimbursed through CACFP

35. Weekly schedule limits time to shop more than once per week

\begin{abstract}
35. Weekly schedule limits time to shop more than once per week
\end{abstract}

\section{Please describe any other barriers not listed above.}


37. How often do you or your providers see a child who does not appear to be getting enough food to eat at home?

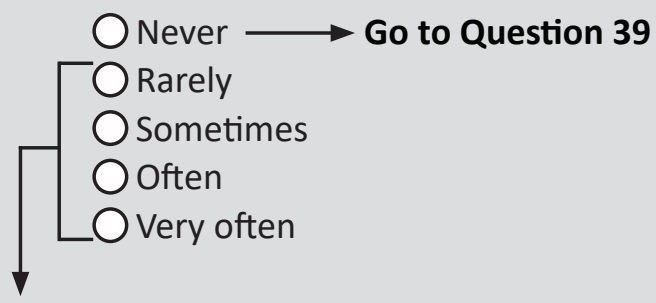

38. When you or your providers see a child who does NOT appear to be getting enough food to eat at home, which of the following do they do?

(check all that apply)

$\square$ Feed the child more on Mondays and Fridays to make up for the child not eating enough food at home during the weekend

$\square$ Keep additional food on hand to feed the child

$\square$ Give food to the family to take home for the child to eat

$\square$ Refer the family to the Special Supplemental Nutrition Program for Women, Infants, and Children (WIC)

$\square$ Refer the family to the Supplemental Nutrition Assistance Program (SNAP) [Formerly known as the Food Stamp Program]

$\square$ Other (please specify):
39. In general, how does your program make sure that there is enough food for everyone at meals?

(check all that apply)

$\square$ Providers pay close attention to make sure that children do not take too much food

$\square$ Providers serve children to make sure there is enough food for everyone

$\square$ Providers tell children how much food to serve themselves

$\square$ Serving cups or utensils are provided that hold the amount of food that children should take

This question does not apply. Food arrives already portioned on each child's plate

$\square$ This question does not apply. There is usually more than enough food available

\section{Meal Time Practices: Difficulty Level}

40. Providers sit with children during meals and snacks

41. Providers eat together with children during meals and snacks

42. Providers eat only the food and beverages that are being served to children during meals and snacks

Is your program currently doing this?

Yes No

$\mathrm{O}$

O 0

O 0

43. Meals and snacks are served family style where children always choose and serve most or all foods themselves

44. Children help with setting and clearing the table during meals and snacks

45. Providers enthusiastically role model eating healthy foods served at meal and snack times. For example, "Mmm, these peas taste yummy!"
How difficult is it to do (or potentially do)?

Not at all A little Kind of Very difficult difficult difficult difficult
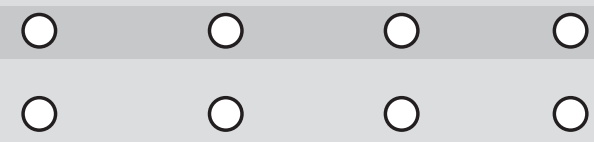

$0 \quad 0 \quad 0$

$\bigcirc \quad 0 \quad 0$

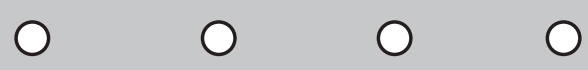

$\bigcirc$

$\bigcirc$

$\bigcirc$ 
Is your program

\section{currently doing this?}

Yes No

46. Providers talk about healthy foods with the children at mealtime (e.g., which vegetables they like)

47. Providers praise children for trying new or less preferred foods

48. Providers do not praise children for finishing food or cleaning their plates

49. When children request seconds, providers ask them if they are still hungry before serving more food.

50. Providers allow children to decide when they are full during meal and snack times

51. When children eat less than half of a meal or snack, providers ask them if they are full before removing their plates

52. Providers do not use food to calm upset children or encourage appropriate behavior

53. Providers use children's preferred foods to encourage them to try less preferred foods (This includes offering a treat only if a child finishes his/her vegetables)
O $\mathrm{O}$

○ 0

○ 0

O 0

○ 0

○ 0

○ 0

0
How difficult is it to do (or potentially do)?

Not at all A little Kind of Very difficult difficult difficult difficult ?
O

O

O

O

O

O

$\mathrm{O}$

O

O

O

0

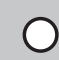

O

O

0

O

O

O

0

O
○

O

O

O

O

O

O

O

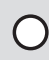

O 


\section{Nutrition Education}

For each of the following statements, please mark how often these events occur.

63. Structured nutrition education is incorporated into daily routines through lesson plans, books, posters and hands-on activities.
Rarely or never
O1 time per month
2-3 times per month
O1 time per week or more

64. Providers talk with children informally about healthy eating during mealtime.
Rarely or never
O1 time per month
2-3 times per month
O1 time per week or more

65. Children are involved in hands-on sensory food experiences (for example, tasting, smelling, and touching food)
Rarely or never
O1 time per month
2-3 times per month
O1 time per week or more

66. How often do providers receive professional development on child nutrition? (Please do not include training on food safety or food program guidelines. This can include taking in-person or online training for contact hours or continuing education credits. It can also include information presented at providers meetings.)

ONever

Less than one time per year

One time per year

OTwo or more times per year

\section{Engaging Parents/Guardians}

67. How often are families are offered education on child nutrition? (Education can be offered through in-person educational sessions, brochures, tip sheets, or your program's newsletter, website, or bulletin boards.)

ONever

$\bigcirc$ Less than one time per year

One time per year

OTwo or more times per year
68. During the last year, which of the following parent engagement activities has your program used?

(check all that apply)

$\square$ Routinely communicated with parent/guardian regarding child's daily food and beverage consumption

$\square$ Gave written information (such as flyers, or newsletters) about healthy eating (trying new food etc.).

$\square$ Discussed healthy eating at parent-provider conferences

$\square$ Encouraged healthier items for holiday/ celebration foods

69. Please describe any other parent engagement activities your program has used during the last year.

The list below includes possible barriers for engaging parents or guardians to encourage children's healthy eating. For each statement, please answer yes if it is a barrier your program faces, or no if not.

Yes No

70. Parents do not have time to talk with the provider about children's nutrition

71. Parents have cultural beliefs about food that are not always consistent with healthy eating

72. Parents do not have enough money to purchase healthy foods

73. Parents are too busy to prepare healthy foods

74. Providers do not want to offend parents

75. Parents or guardians do not like the taste of healthy foods themselves

76. Providers are uncertain how to engage parents.

77. Parents prioritize other food related topics such as allergies or children's food intake over healthy eating

78. Please describe any other barriers not listed above.

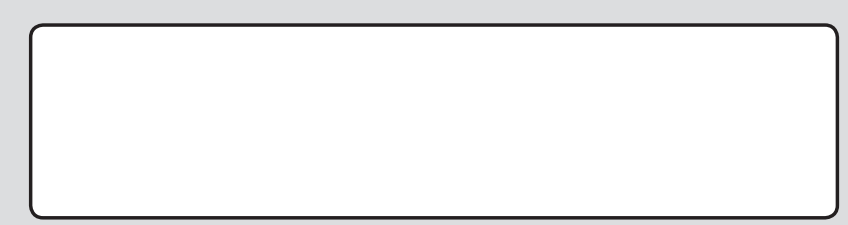




\section{Access to Training}

79. Do you have internet access at the childcare site or elsewhere?

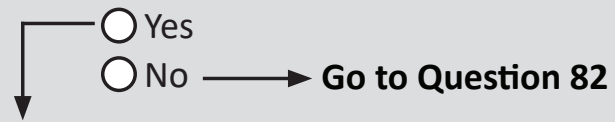

80. Would you describe your internet access as reliable and consistent? (That is, you could stream videos for training purposes?)
OYes
ONo

81. How do you access the internet? (check all that apply)

$\square$ Desktop computer on-site

$\square$ Laptop computer

$\square$ Tablet

$\square$ Mobile phone

82. When you participate in nutrition related training, what is your motivation for participating?

(check all that apply)

$\square$ To stay updated with best practices

$\square$ To grow and improve job performance as a professional

$\square$ Topic was interesting, new, or different

$\square$ Licensure or regulatory requirements

$\square$ To better meet children's special needs

$\square$ Passion for job/love of children

$\square$ Network and meet other providers

$\square$ Help educate children and prepare for school

$\square$ CACFP requirement

$\square$ Accreditation requirement

$\square$ Other (please specify):

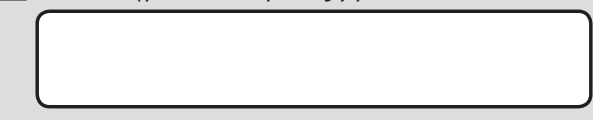

I do not participate in training
83. Which of the following are barriers that prevent you from obtaining training? (check all that apply)

$\square$ Cost of the training

$\square$ Unable to travel to the training location

$\square$ scheduled trainings do not fit within my work schedule (outside of usual hours)

$\square$ Leaving my work site would leave the other providers short-handed

$\square$ Training has not been made available in the past

$\square$ Not interested in training topics

$\square$ Lack of internet or computer access

$\square$ Trainings are hard to find in my area

Unsure if the training qualifies for new license rules

Other (please specify):

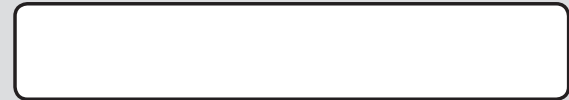

None of the above

84. What is your preference when it comes to receiving training? (check all that apply)

$\square$ In-person training

$\square$ Live webinar (allows for question and answer with the host)

$\square$ On-going mentorship/coaching

$\square$ On-going peer-to-peer with other providers

$\square$ On-line learning modules with videos that can be viewed at any time

$\square$ Attending conferences with multiple trainings on one day (like a Saturday)

$\square$ Other (please specify):

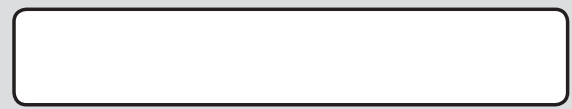

No preference 
85. If you wanted to improve healthy eating practices in your childcare program, how likely would you be to consult the following sources for advice and information?

\begin{tabular}{|c|c|c|c|c|c|}
\hline & $\begin{array}{c}\text { Very } \\
\text { unlikely }\end{array}$ & Unlikely & Neutral & Likely & $\begin{array}{l}\text { Very } \\
\text { likely }\end{array}$ \\
\hline a. Google search & O & O & O & O & O \\
\hline b. Social Media - Facebook & 0 & 0 & 0 & O & 0 \\
\hline c. Social Media - Pinterest & O & 0 & O & O & O \\
\hline d. Social Media - Twitter & O & 0 & O & O & O \\
\hline e. Family Doctor/Pediatrician & O & 0 & 0 & O & 0 \\
\hline f. Dietitian/Nutrition Educator & O & 0 & O & O & 0 \\
\hline g. Family Members & O & 0 & O & O & O \\
\hline h. Nebraska Extension & O & 0 & O & O & O \\
\hline i. Child and Adult Food Program & O & O & O & O & O \\
\hline j. Other childcare providers & O & O & O & O & O \\
\hline \multicolumn{6}{|l|}{ k. Other (please specify): } \\
\hline & O & O & 0 & 0 & O \\
\hline
\end{tabular}

86. In your opinion, how much of a health problem is obesity among children in your program?

Not a problem

OA small problem

OA problem

A large problem

\section{About You}

\section{What is your job title?}

OCenter Director

OFamily Childcare Provider

OProgram Nutrition Specialist

Program Education Specialist

OOther (please specify):

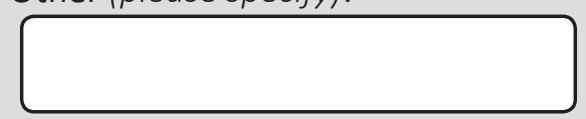

88. How many years have you been working in the early childhood field? (enter 0 if less than one year)

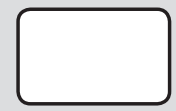

89. What is your age?

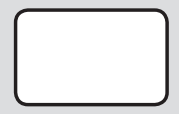

90. What is your gender?
OMale
Female
$\mathrm{O}$

91. Are you Hispanic or Latino/a/x?

OYes
Ono

92. What is your race(s)? (check all that apply)

$\square$ American Indian or Alaskan Native
$\square$ Asian
$\square$ Black or African American
$\square$ Native Hawaiian or Pacific Islander
$\square$ White or Caucasian
$\square$ Other (please specify):

93. What is the highest degree you have completed?

OSome high school

OHigh school graduate or GED

OSome college

2-year degree (Associate's)

4-year degree (Bachelor's)

Graduate or Professional degree

Thank you! We greatly appreciate the time you have taken to complete this survey. For your convenience, please use the postage-paid return envelope included in your survey packet to return your questionnaire. Questions or requests from this survey can be directed to:

Bureau of Sociological Research University of Nebraska-Lincoln Phone: 1-800-480-4549 (toll free) E-mail: bosr@unl.edu 